\title{
Pseudomonas aeruginosa en la otitis externa canina: situación actual
}

\author{
Pseudomonas aeruginosa in canine otitis externa: current situation
}

\author{
Broglia Guillermo ${ }^{1}$, Buchamer Andrea ${ }^{1}$, Mestorino nora ${ }^{1}$, Marchetti laura ${ }^{1 *}$
}

1. Laboratorio de Estudios Farmacológicos y Toxicológicos (LEFyT). Cátedra de Farmacología

Especial y Toxicología. Facultad de Ciencias Veterinarias, Universidad Nacional de La Plata.

* Correo electrónico de la autora de contacto: mlmarchetti@fcv.unlp.edu.ar

\begin{abstract}
Resumen
La otitis externa es una enfermedad de presentación frecuente en la práctica diaria. La comprensión de su fisiopatología es importante para su prevención, diagnóstico y tratamiento. El protocolo diagnóstico debe ser estricto, siendo fundamental el rol que cumplen en estos casos el cultivo bacteriano y el antibiograma. Pseudomonas aeruginosa es un microorganismo oportunista e invasor, que constituye en sí mismo un factor perpetuante para las otitis crónicas. Además de sus factores de virulencia y la resistencia intrínseca a múltiples fármacos, forma biopelículas de protección sobre tejidos colonizados y posee gran capacidad para adquirir genes determinantes de resistencia cromosómica y extra cromosómica durante el tratamiento. Los casos crónicos o recurrentes con aislamientos de P. aeruginosa resultan un desafío constante para el veterinario. El oído externo tiene escasa irrigación, por lo cual los antimicrobianos sistémicos no alcanzan concentraciones adecuadas, siendo la terapia tópica la primera elección. El éxito terapéutico evoluciona hacia la aplicación de pautas farmacocinéticas/farmacodinámicas, desde una concepción netamente empírica hasta una concepción cuantitativa, permitiendo describir y simular el efecto de un antibiótico sobre una población bacteriana en función del tiempo, mediante la modelización matemática de los datos experimentales, con objeto de maximizar la eficacia y minimizar fenómenos de resistencia.
\end{abstract}

\section{Palabras clave}

Otitis externa, Pseudomonas aeruginosa, antimicrobianos, PK/PD, canino

\begin{abstract}
Otitis externa is a frequent disease in veterinary small animal practice. Understanding its pathophysiology is important for prevention, diagnosis, and treatment. The diagnostic protocol must be strict, where bacterial culture and antibiogram play an essential role. Pseudomonas aeruginosa is an opportunistic and invasive microorganism, which by itself constitutes a perpetuating factor for chronic otitis. In addition to its virulence factors and intrinsic resistance to multiple drugs, it forms protective biofilms on colonized tissues, and has a great capacity to acquire genes that determine chromosomal and extra chromosomal resistance during the antibiotic treatment. Management of chronic or recurrent cases of otitis by $P$. aeruginosa is a constant challenge for veterinarians. Since the outer ear is a scarcely irrigated tissue, the use of systemic antimicrobials does not reach adequate local concentrations, leaving topical therapy as the first choice of treatment. Treatment success should consider application of pharmacokinetic/pharmacodynamic guidelines not only from a purely empirical conception, but also from a quantitative conception, which allows description and simulation ofthe effect of an antibiotic on a bacterial population as function of time through mathematicalmodelling of the experimental data, in order to maximize the effectiveness and minimize resistance selection.
\end{abstract}

\section{Key words}

Otitis externa, Pseudomonas aeruginosa, antimicrobials, PK/PD, canine

Fecha de recepción: 20/03/2020

Fecha de revisión: 15/05/2020

Fecha de aprobación: 04/06/2020
ANalecta Vet 2020; Enero-Junio; 40(1):13-24

Impresa ISSN 03655 14-8 Electrónica ISSN 1514-2590

doi.org/10.24215/15142590e048 


\section{Introducción}

La otitis externa (OE) es una enfermedad común y reconocida en la práctica clínica diaria por los veterinarios. Se estima que aproximadamente $10-20 \%$ de los caninos que concurren a la consulta presentan algún grado de otitis externa. El 50 \% de los casos son crónicos y la membrana timpánica puede encontrarse lesionada, posibilitando la extensión de la infección hacia el oído medio (Pulido et al., 2010).

El oído externo se encuentra compuesto por el pabellón auricular y el meato acústico externo. Es la porción visible y externa del oído responsable de captar y transportar las ondas sonoras, para dirigirlas luego hacia la membrana timpánica, es decir, hacia el oído medio. El pabellón auricular u oreja se compone de un cartílago auricular recubierto de piel, mientras que el conducto o meato auditivo externo (CAE) es el canal entre el pabellón y la membrana timpánica, cuya estructura histológica es similar a la de la piel, con un epitelio estratificado queratinizado con sus correspondientes anexos dérmicos, folículos pilosos y glándulas sebáceas y ceruminosas asociadas (Cole, 2009). Se define a la OE como la inflamación cutánea del CAE y, por extensión, de las diferentes zonas del pabellón auricular, ya que frecuentemente el proceso se extiende a la cara cóncava, interna de las orejas (Paterson, 2016b).

Desde el punto de vista clínico las OEs pueden ser uni o bilaterales, agudas o crónicas, leves o graves, recurrentes o no. De acuerdo con el tipo de exudado se clasifican en eritematoceruminosas o supurativas. También se puede establecer en dicha clasificación el subgrupo de parasitarias y no parasitarias, encontrándose entre estas últimas las producidas por levaduras y por bacterias (Terziev \& Borissov, 2017).

La OE crónica o recurrente se define como aquella que perdura más de un mes, y el término recurrente puede establecerse como la presencia de más de un episodio de otitis en el transcurso de un año (Griffin, 2011). Es un problema difícil y frustrante para resolver por parte del veterinario clínico generalista; es por ello que, a menudo, se requiere la derivación del caso a un especialista dermatólogo debido a la complejidad de su evolución. El conocimiento de la enfermedad del oído, sobre todo la crónica o recurrente, requiere la detección precisa de la/s causa/s primaria/s y secundaria/s, así como de los factores predisponentes y perpetuantes (Paterson \& Matyskiewicz, 2018; Zur et al., 2011). Esto implica hacer hincapié en la observación de cambios en la anatomía macro y microscópica, en el conocimiento de la fisiología del oído y en la utilización del equipamiento necesario para evaluarlo que, en algunos casos, implica técnicas sofisticadas como la videoendoscopía (Griffin, 2011).

La inflamación crónica del CAE redunda en alteraciones fundamentales en la estructura de este. El CAE está revestido por una piel delgada, que contiene glándulas apocrinas modificadas que producen cerumen. En los procesos inflamatorios crónicos estas glándulas sufren cambios hiperplásicos y producen cerumen en exceso. A su vez, también se genera un engrosamiento dermoepidérmico (fibrosis) de los pliegues de la oreja y del propio CAE, lo que se traduce en una reducción efectiva de su diámetro. En los casos más graves, el CAE puede llegar a cerrarse por completo, se inhibe la migración natural de las células epiteliales, que constituye un mecanismo de defensa natural y se puede producir la ruptura de la membrana timpánica, lo que facilita que productos de desecho y microorganismos alcancen el oído medio. La calcificación del cartílago auricular y del CAE es un evento terminal de la inflamación crónica (Broglia \& Borrelli, 2014) (Figuras 1 y 2).

Los cambios crónicos favorecen la proliferación de bacterias y levaduras, las que contribuyen a perpetuar la afección (Scott et al., 2001). Estos generan lesiones secundarias debido a la irritación crónica y a la proliferación excesiva de microorganismos (Jacobson, 2002). Los animales afectados, además de prurito intenso y otorrea, pueden presentar dolor muy severo en casos graves.

La identificación clara del cuadro clínico es un paso importante, pero tratar adecuadamente las OEs ya es una cuestión más compleja. Por lo expuesto, el objetivo de la presente revisión fue realizar una actualización de las otitis externas crónicas ocasionadas por Pseudomonas aeruginosa en caninos, haciendo hincapié en la importancia del conocimiento de la compleja fisiopatología de las otitis externas, la metodología diagnóstica, el reconocimiento de los principales mecanismos de resistencia del microorganismo y las posibles estrategias terapéuticas, tanto actuales como futuras.

\section{Fisiopatología de las otitis externas}

En la fisiopatología de las OEs intervienen cuatro tipos de causas y factores:(1) factores predisponentes, (2) causas primarias o desencadenantes, (3) causas secundarias y (4) factores perpetuantes o agravantes (Saridomichelakis et al., 2007). La interacción que se produce entre ellos da como resultado los cuadros clínicos que observamos en la práctica diaria (Tabla 1).

\section{Diagnóstico de la otitis externa}

Durante mucho tiempo, cuando un paciente presentaba una enfermedad en el oído, se examinaba y se trataba solamente el órgano afectado. El enfoque actual es totalmente diferente, ya que, a partir de los avances en el conocimiento de la fisiopatología de las OEs, el CAE es considerado una extensión especializada de la piel y, por lo tanto, las OEs son consideradas un 


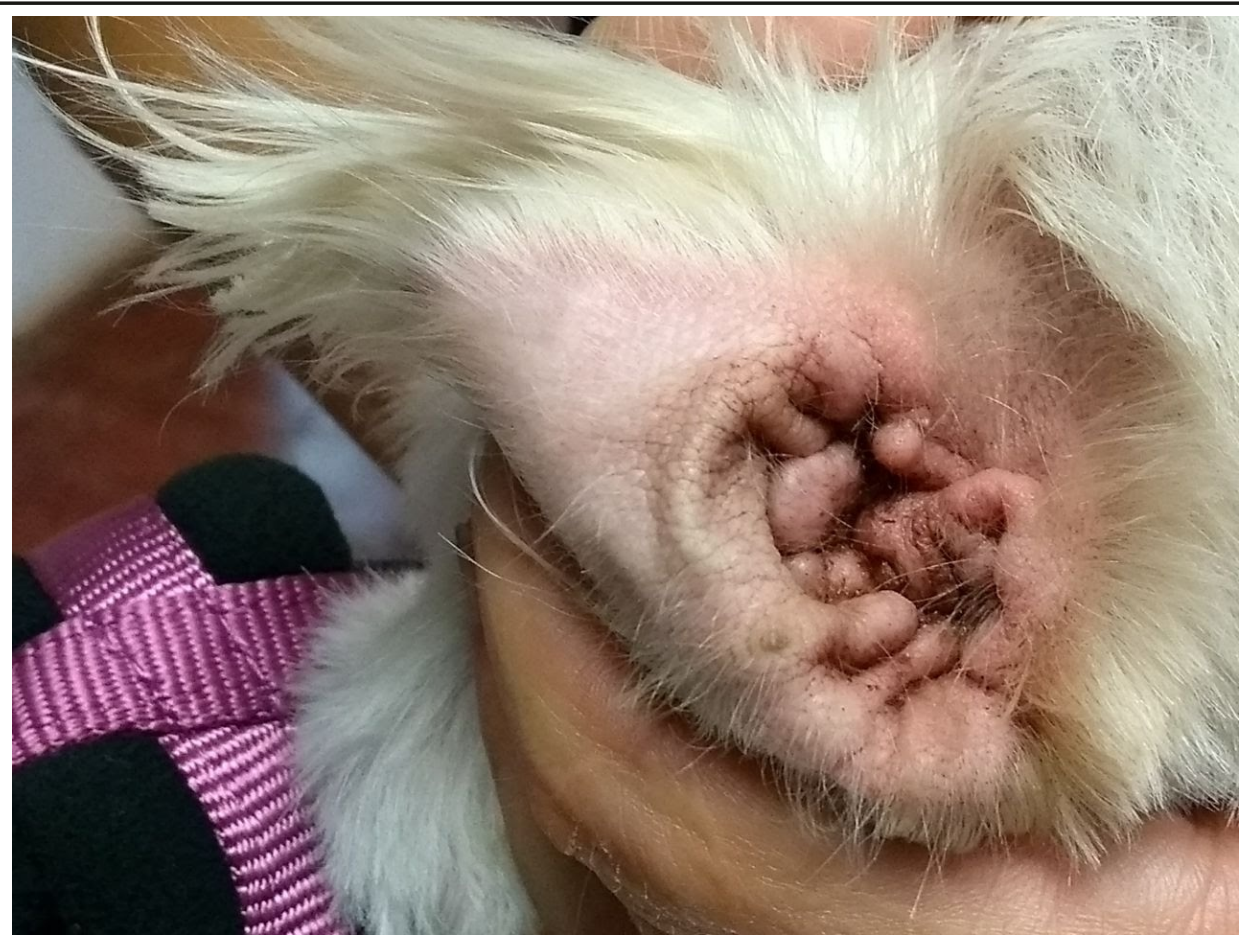

Figura 1. Hiperplasia y liquenificación de los pliegues de la oreja en un canino con otitis crónica que conduce a una disminución del diámetro del conducto auditivo externo.

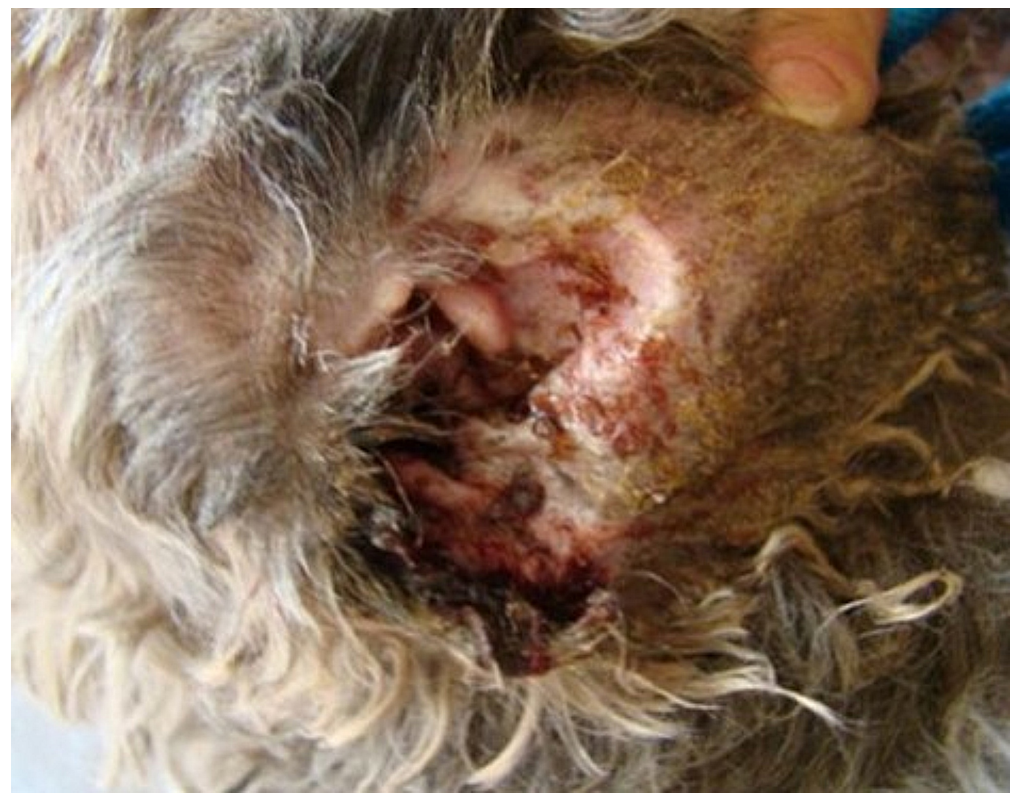

Figura 2. Abundantes exudados en la cara medial de la oreja de un canino con otitis externa por Pseudomonas aeruginosa con presencia de costras y erosiones secundarias al rascado.

problema dermatológico.

El diagnóstico clínico de las OEs es relativamente sencillo. Los animales afectados presentan grados variables de prurito, dolor, mal olor y exudados de diferentes tipos, desde ceruminosos, en los casos más leves, hasta purulentos, en los casos más graves, generalmente en OEs crónicas y recidivantes. El otohematoma es una complicación que puede aparecer cuando existe prurito intenso asociado (Scott et al., 2001). El desafío diagnóstico más importante consiste en tratar de identificar las causas primarias de la $\mathrm{OE}$ (Paterson, 2016a; Paterson \& Matyskiewicz, 2018) y determinar claramente cuáles son las causas secundarias y los factores perpetuantes.

Por todo lo expuesto, además del examen dermatológico general y en particular del oído, en la evaluación del paciente con $\mathrm{OE}$ se deberían 


\begin{tabular}{|c|c|c|}
\hline Factores & Características & Ejemplos \\
\hline $\begin{array}{l}\text { Factores } \\
\text { predisponentes }\end{array}$ & $\begin{array}{l}\text { Características del propio } \\
\text { animal que incrementan el } \\
\text { riesgo del desarrollo de } \mathrm{OE}\end{array}$ & $\begin{array}{l}\text { - CAE anormalmente pequeño o } \\
\text { estrecho (Ej: Sharpei) } \\
\text { - Exceso de humedad en el CAE (Ej: } \\
\text { razas con orejas pendulares) } \\
\text { - Hipertricosis en el CAE (Ej: razas toy) }\end{array}$ \\
\hline $\begin{array}{l}\text { Causas } \\
\text { primarias o } \\
\text { desencadenantes }\end{array}$ & $\begin{array}{l}\text { Son las responsables directas } \\
\text { del desarrollo de OE }\end{array}$ & $\begin{array}{l}\text { - Enfermedades alérgicas } \\
\text { (dermatitis atópica, alergia alimentaria) } \\
\text { - Enfermedades endocrinas } \\
\text { (hipotiroidismo) } \\
\text { - Parásitos } \\
\text { (Otodectes cynotis, Demodex canis) } \\
\text { - Traumatismos } \\
\text { (iatrogénico o autoinducido) }\end{array}$ \\
\hline $\begin{array}{l}\text { Causas } \\
\text { secundarias }\end{array}$ & $\begin{array}{l}\text { Contribuyen o causan el } \\
\text { desarrollo de OE en oídos } \\
\text { anormales o cuando existen } \\
\text { factores predisponentes }\end{array}$ & $\begin{array}{l}\text { - Bacterias (Pseudomonas aeruginosa, } \\
\text { Staphylococcus spp., Streptococcus } \\
\text { spp., Escherichia coli, Proteus spp., y } \\
\text { Klebsiella spp.) } \\
\text { - Levaduras (Malassezia pachydermatis) }\end{array}$ \\
\hline $\begin{array}{l}\text { Factores } \\
\text { perpetuantes } \quad y \\
\text { agravantes }\end{array}$ & $\begin{array}{l}\text { Son los que impiden la } \\
\text { resolución de la OE. Están } \\
\text { vinculados a los cambios } \\
\text { estructurales e inflamatorios } \\
\text { que se producen en el oído, } \\
\text { asociados a procesos } \\
\text { patológicos crónicos }\end{array}$ & $\begin{array}{l}\text { - Liquenificación } \\
\text { - Hiperqueratosis } \\
\text { - Hiperplasia sebácea } \\
\text { - Ulceraciones } \\
\text { - Tumores } \\
\text { - Otitis media }\end{array}$ \\
\hline
\end{tabular}

Tabla 1. Factores y causas que intervienen en la fisiopatología de la OE.

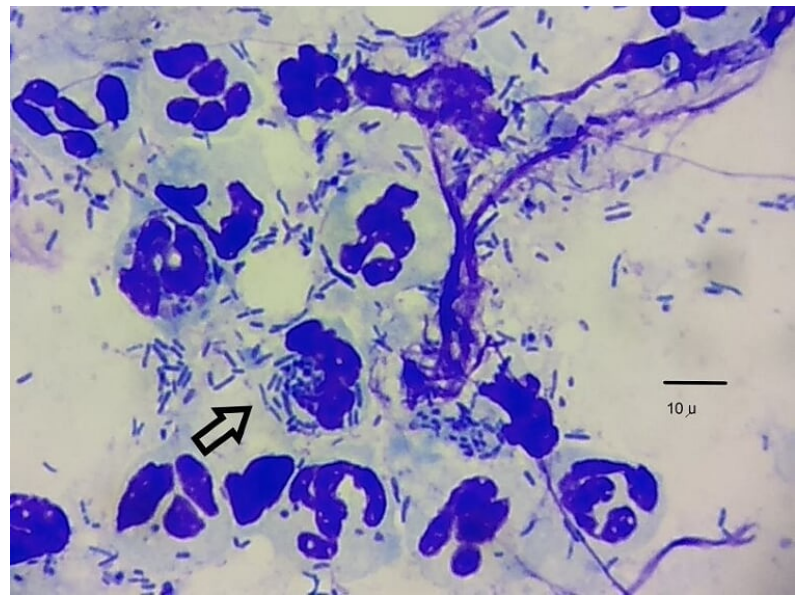

Figura 3. Citología de exudado ótico de un canino con otitis externa crónica por Pseudomonas aeruginosa en la que se observa una abundante cantidad de bacilos, escasos cocos PMN neutrófilos y macrófagos. La flecha muestra un mácrófago fagocitando. Tinción de Giemsa. Barra= $10 \mu \mathrm{m}$. (Gentileza MV Huberto von Guradze).

incluir dentro de la rutina diagnóstica, como mínimo, una otoscopia, el examen directo y el estudio citológico de los exudados. La otoscopia se utiliza para evaluar el diámetro del canal auditivo, la cantidad y tipo de exudado y la presencia de úlceras, cuerpos extraños, parásitos o tumores, así como la integridad de la membrana timpánica. La

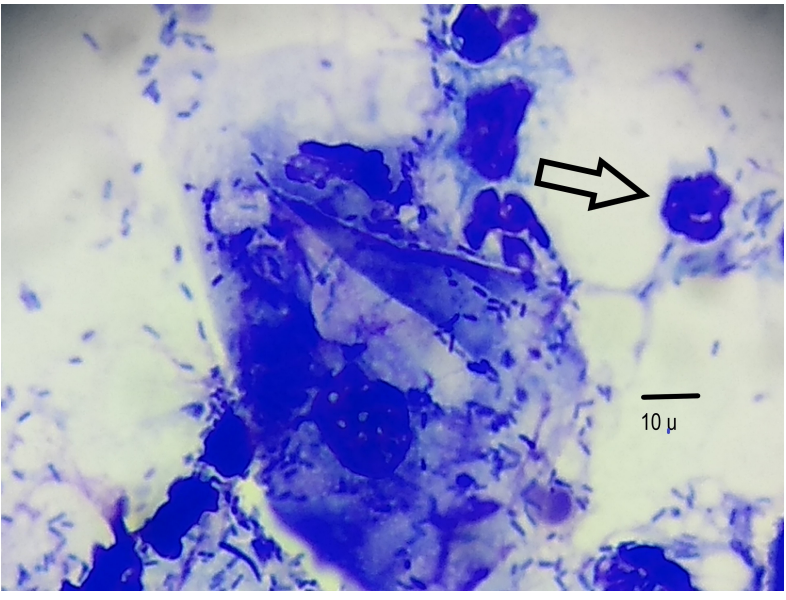

Figura 4. Imagen de fagocitosis (flecha) en un estudio citológico de un canino con otitis crónica por Pseudomonas aeruginosa. Se observan bacterias, mácrofagos y PMN neutrófilos. Tinción de Giemsa. Barra $=10 \mu \mathrm{m}$. (Gentileza MV Huberto von Guradze).

citología de los exudados óticos constituye una herramienta de singular importancia para el diagnóstico de las OEs (Nuttall, 2016; Scott et al., 2001). La toma de muestras para realizar este estudio es un procedimiento muy sencillo que se realiza con un hisopo y se obtiene de la porción horizontal del CAE. Las muestras se reparten 
sobre dos portaobjetos. Sobre uno se coloca aceite mineral para el examen directo de parásitos, y el otro se tiñe con una coloración para células (MayGrünwald o Tinción $15^{\circledR}$ ), lo que permite, en las OEs crónicas bacterianas, observar: cantidad y morfología de bacterias, cantidad y tipo de leucocitos y evidencias de fagocitosis (Figuras 3 y 4).

Para el caso de las otitis bacterianas crónicas y recurrentes, el cultivo y el antibiograma constituyen herramientas clave e irremplazables. Las características de los cultivos y la sensibilidad bacteriana en caninos con otitis externa han sido extensamente estudiadas a lo largo de los años; sin embargo, existe gran variabilidad en los resultados en cuanto a la prevalencia de los microorganismos aislados y los perfiles de sensibilidad obtenidos (Escribano et al., 2009; Sánchez et al., 2011; Bugden, 2013; Ngo et al., 2018).

\section{Microbiología de las otitis externas}

En el $70 \%$ de los casos de OE en caninos los microorganismos aislados son levaduras, principalmente Malassezia pachydermatis, estrechamente relacionada con otitis ceruminosas secundarias a procesos alérgicos y a tratamientos inadecuados con soluciones antibióticas. Con menor frecuencia, se aíslan Candida, Aspergillus, Trichophyton y Microsporum (Hariharan et al., 2006; Oliveira et al., 2008).

En aproximadamente un $30 \%$ de los casos, generalmente los más graves, bacterias grampositivas y gramnegativas intervienen en la fisiopatología de las OEs y se perpetúan en el conducto auditivo, complicando el cuadro inicial e impidiendo la curación. En caninos, los aislamientos más frecuentemente reportados son: Staphylococcus pseudintermedius (36-70 \%) y Pseudomonas aeruginosa (3-18 \%) y, en menor medida, Streptococcus spp, Proteus spp y Escherichia coli (menos del 10 \%) (Hariharan et al., 2006; Oliveira et al., 2008). Otros autores han cuantificado en caninos un $38 \%$ de los casos con presencia de cocos y un $22 \%$ de bacilos (Saridomichelakis et al., 2007). Estudios más recientes referidos a los microorganismos aislados con mayor frecuencia reportan algunas variaciones: $P$. aeruginosa (35,5 \%), S. pseudintermedius (24,3 \%), Proteus sp. (6,8 \%), Streptococcus $\beta$-hemolíticos $(6,2 \%), y$ E. $\operatorname{coli}$ (4,2 \%) (Bugden, 2013; Petrov et al., 2013).

\section{Pseudomonas aeruginosa}

Pseudomonas aeruginosa es un microorganismo ubicuo, que se encuentra en agua, suelos y plantas con relativa frecuencia. Desarrolla mejor en ambientes aeróbicos, es muy versátil nutritivamente y no fermenta hidratos de carbono, pero produce ácido a partir de azúcares como glucosa, lactosa y fructosa o sacarosa. Es capaz de desarrollarse a temperaturas superiores a los $42{ }^{\circ} \mathrm{C}$. De los bacilos gramnegativos aislados en muestras de OE canina crónica, $P$. aeruginosa es el más frecuente. Se lo considera un microorganismo oportunista e invasor (Bergey \& Holt, 1994; Berthelot et al., 2005).

Esta bacteria tiene una extraordinaria capacidad para defenderse, generada por su resistencia natural frente a muchos antimicrobianos, su capacidad de formar biopelículas en el tejido colonizado, su sistema biológico complejo, su gran resistencia frente a la respuesta inmunológica del hospedador y su capacidad de seleccionar mecanismos de resistencia múltiple. Posee, además, una compleja membrana externa que limita el paso de nutrientes y otras sustancias como los antimicrobianos (Rasamiravaka et al, 2015).

La gran cantidad de factores de virulencia estructurales (cápsula de exopolisacáridos, adhesinas, pilis, pigmentos difusibles, endotoxinas), toxigénicos (exotoxinas $\mathrm{A}, \mathrm{S}$ y $\mathrm{T}$ ) y enzimáticos (elastasa, proteasa alcalina, ramnolípido, fosfolipasa C) explican, en parte,la razón por la cual la $P$. aeruginosa es capaz de generar tanta variedad de infecciones (Mandell et al., 2012).

La habilidad de formación de biopelícula tiene gran importancia clínica, ya que impide la correcta llegada de los antimicrobianos hasta los microorganismos, constituyéndose en un verdadero reservorio de protección para las bacterias. Estas también favorecen el fenómeno de resistencia a los antimicrobianos (Nuttall, 2016).

Los factores de virulencia del microorganismo y el deterioro de la inmunidad de los pacientes afectados (siendo, en el caso puntual de la OE canina, la vulnerabilidad de la piel lesionada por la afección de base con pérdida del efecto de barrera física de defensa), desempeñan un importante papel como factores agravantes para la colonización del mencionado patógeno. Estudios recientes, empleando un modelo de ratón, han demostrado que las lesiones ocasionadas en piel por quemaduras causan deterioro de la producción de péptidos de defensa ( $\beta$-defensinas) que desempeñan un papel primario en la barrera inmunológica frente a esta bacteria invasora (Kobayashi et al., 2008; Mandell et al., 2012).

En cuanto a la resistencia a los antimicrobianos, $P$. aeruginosa tiene ciertas características que hacen que sea naturalmente resistente a algunos fármacos, como la baja permeabilidad de la membrana externa, la expresión intrínseca o inducida de bombas de eflujo y la producción de enzimas $\beta$-lactamasas (Lin et al., 2012). Es por ello que la terapia puede resultar ineficaz cuando se emplean fármacos como ampicilina, cefalosporinas de primera y segunda generación, eritromicina $\mathrm{y}$, con relativa frecuencia, también tetraciclinas y cloranfenicol. Además, sumado al fenómeno de resistencia intrínseca, $P$. aeruginosa tiene gran 
capacidad para adquirir y/o expresar genes determinantes de resistencia, durante el curso de un tratamiento antimicrobiano, en el ADN cromosómico o bien extra cromosómico (integrones, transposones, plásmidos). Es por ello que existen fenotipos de resistencia muy variables, por lo cual la utilización de antimicrobianos de manera empírica lleva con frecuencia al fracaso terapéutico. Es fundamental la correcta toma de muestras, el aislamiento y la tipificación fenotípica de este microorganismo para lograr el éxito terapéutico en la $\mathrm{OE}$ canina por $P$. aeruginosa (Livemore, 2002; Lin et al., 2012; Petersen et al., 2002).

En medicina humana, se ha evidenciado que en el 10,2 \% de los tratamientos antimicrobianos frente a $P$. aeruginosa es factible aislar, al menos, una cepa resistente que antes de la terapia presentaba un fenotipo sensible (Gómez Álvarez et al., 2005). Esta selección de la resistencia varía dependiendo de cada antibiótico. Por ejemplo, ceftazidima, una cefalosporina de tercera generación con actividad anti-pseudomonas, registra el más bajo riesgo de selección de determinantes genéticos de resistencia en bacterias previamente sensibles a ella. En contraste, imipenem presenta la más alta tasa de selección de resistencia (Cabot et al., 2016). Lo preocupante, son las pocas opciones que quedan para el efectivo tratamiento de las infecciones por microorganismos resistentes a múltiples antimicrobianos. Los antimicrobianos que se consideran con buena actividad son: penicilinas antipseudomonas (piperacilina, ticarcilina, carbenicilina, azlocilina) asociadas a inhibidores de B-lactamasas, ceftazidima, cefepima, monobactámicos como aztreonam, carbapenémicos (imipenem y meropenem), quinolonas (especialmente ciprofloxacina) y aminoglucósidos. Sin embargo, ante el surgimiento de aislamientos multirresistentes, a veces, es necesario acudir a antibióticos que se consideraban fuera de uso por su alta toxicidad, como las polimixinas. Los principales mecanismos de resistencia en $P$. aeruginosa comprenden: presencia de $\beta$-lactamasas y alteraciones de la permeabilidad de membrana dadas por la presencia de bombas de eflujo y las mutaciones de las porinas transmembranales.

\section{Tratamiento de las OEs por Pseudomonas aeruginosa}

El objetivo del tratamiento médico en los perros con predisposición conocida para desarrollar OEs crónicas es precisamente evitar el deterioro que conduzca a que el tratamiento quirúrgico pase a transformarse en la única opción. El tratamiento de la $\mathrm{OE}$ incluye varios aspectos: identificación de factores predisponentes y primarios, limpieza del CAE, terapia tópica, en ocasiones terapia sistémica, educación del propietario, seguimiento preventivo y mantenimiento (Nuttall, 2016).

En primer lugar, es de fundamental importancia la identificación de los factores predisponentes y las causas primarias. Muchas veces, en los casos crónicos, esto resulta claramente dificultoso por la influencia de las causas secundarias y los factores perpetuantes que también forman parte de la compleja fisiopatología de las OEs.

El segundo paso es la limpieza del conducto auditivo externo. Limpiar y secar el CAE es una parte esencial de la evaluación y el tratamiento (Rosychuk \& Luttgen, 2000; Scott et al., 2001). La limpieza permite una mejor exploración del CAE, reduce la población microbiana y sus subproductos, como toxinas y enzimas, facilita la llegada de los fármacos tópicos a su sitio de acción, aumenta la eficacia de medicamentos tópicos (algunos de los cuales pueden ser inactivados por los exudados) y tiene un cierto efecto calmante. Los detritus que no son eliminados pueden actuar como pequeños cuerpos extraños y perpetuar la infección.

Para la limpieza, generalmente se utiliza una solución ceruminolítica (detergentes o surfactantes como dioctilsulfosuccinato de sodio, propilenglicol, glicerina o aceite mineral) y una solución de secado. Todos son potencialmente ototóxicos y no se deberían utilizar si se sospecha de ruptura de la membrana timpánica. Otras soluciones de lavado pueden ser: cloruro de sodio 0,9 \%, agua, ácido acético, clorhexidina o yodopovidona. La solución salina es la única que no daña el oído medio, por lo que puede ser usada regularmente, incluso en otitis severas.

El acceso de los principios activos varía según el tipo de exudado, germen presente y estado de la membrana timpánica.

\section{Terapia tópica}

La terapia tópica constituye una parte muy importante del tratamiento de las OEs debido a la escasa irrigación de estos tejidos que dificulta la llegada de los antimicrobianos administrados por vía sistémica.

Tratamientos combinados o la utilización de productos multicompuestos se utilizan con frecuencia debido a que inicialmente, en muchos casos, se observa una mezcla de inflamación, microorganismos e incluso parásitos. La presencia de corticoides en los medicamentos de uso tópico reduce el dolor, el edema y la producción de exudados, permitiendo la llegada de otros principios activos y facilitando la ventilación y el drenaje del conducto auditivo externo.

Luego del lavado se indica un "limpiador", para eliminar los exudados y los microorganismos perpetuantes. Por ejemplo, si el proceso es seco, escamoso y costroso es preferible un producto oleoso, mientras que en otitis húmedas se prefieren los preparados acuosos. Luego, se utilizan antibióticos en la mayoría de los casos inicialmente, aunque pueden ser innecesarios en el mantenimiento y el tratamiento preventivo. Neomicina, cloranfenicol, polimixina $\mathrm{B}$, ciprofloxacina $\mathrm{y}$ 
gentamicina son, con frecuencia, los antimicrobianos incluidos en los preparados tópicos comerciales para el tratamiento de este tipo de afección en perros (Scott et al., 2001).

En cuanto a las otitis externas con aislamiento e identificación de $P$. aeruginosa, es frecuente el uso de compuestos que contengan polimixina B, marbofloxacina o ciprofloxacina (esta última según la farmacopea humana), utilizados en función de los fenotipos de sensibilidad bacteriana in vitro, $\mathrm{y}$ teniendo en cuenta los productos óticos usualmente disponibles en el mercado (Escribano et al., 2009; Hariharan et al., 2006; Nuttall, 2016). Sin embargo, debe tenerse en cuenta que cuando se realizan estudios in vitro los resultados están basados en la concentración de antimicrobiano que se alcanza a nivel sérico, cuando los mismos son administrados de forma sistémica, lo cual difiere de las concentraciones elevadas que se alcanzan con la administración tópica usada para otitis externa (Barnard \& Aiden, 2017).

Es importante destacar que el uso inadecuado de los antimicrobianos es un factor potencial seleccionador de resistencia bacteriana. Por lo tanto, antibióticos potentes como cloranfenicol, gentamicina o ciprofloxacina no están indicados como tratamiento de primera elección. Inicialmente, estas terapias pueden ser efectivas, pero también, con frecuencia, debido a su uso reiterado, contribuyen a favorecer fenómenos de resistencia bacteriana y hacen que el médico veterinario pierda de vista su verdadero objetivo, que es identificar y controlar los factores predisponentes y primarios de la enfermedad (Paterson, 2016a). La terapia tópica debe ser seleccionada sobre la base de los hallazgos clínicos, estudios citológicos, análisis de las causas subyacentes y experiencia personal (Jacobson, 2002; Paterson, 2016b).

\section{Alternativas terapéuticas a los tratamien- tos tradicionales}

En la actualidad existe una creciente actividad en la investigación de nuevas alternativas terapéuticas al uso de los antimicrobianos tradicionalmente utilizados en tratamientos tópicos. Una alternativa la representan los extractos vegetales, con la finalidad de aprovechar los metabolitos secundarios que las plantas utilizan en su defensa contra microorganismos. Sus compuestos con acción antimicrobiana se encuentran mayoritariamente presentes en los aceites esenciales. Estos resultan ser el producto final del metabolismo secundario de plantas aromáticas y se conforman fundamentalmente de terpenos con actividad y composición variada de entre 20 y 60 compuestos (Buldain et al., 2017, 2018). Recientemente, Sim et al. (2019) reportaron los resultados obtenidos en estudios cuantitativos de sensibilidad in vitro (concentración bactericida mínima, concentración inhibitoria mínima y curvas de muerte bacteriana) evaluando la eficacia de aceites esenciales de orégano, tomillo y sus principales componentes fenólicos (carvacrol y timol), frente a diversos patógenos multirresistentes como $S$. pseudintermedius meticilino-resistente y $P$. aeruginosa aislados a partir de pacientes caninos con OE. Los aceites evaluados, el carvacrol y el timol exhibieron actividad antibacteriana contra todos los aislamientos estudiados, resultando prometedor continuar con dicha investigación, ya que aún no existen datos de pruebas realizadas in vivo. En 2018, Neves et al. publicaron un trabajo acerca del aceite esencial de Melaleuca alternifolia o árbol de té común, en el que evaluaron la actividad antimicrobiana in vivo e in vitro frente a microorganismos aislados del oído de pacientes con OE canina ( $S$. pseudintermedius, $S$. aureus, $P$. aeruginosa, Proteus mirabilis y Malassezia pachidermatis). La solución empleada in vivo produjo una significativa remisión de los signos clínicos en los pacientes tratados.

Existe una constante búsqueda de nuevas alternativas naturales; el caso de la miel es otro ejemplo de ello. En 2016, Maruhashi et al. publicaron un trabajo acerca de la eficacia de la miel de grado médico para el tratamiento de la otitis canina. Así, evaluaron la eficacia in vitro e in vivo frente a $S$. pseudintermedius meticilinoresistente, logrando cura clínica en un $70 \%$ de los pacientes caninos. Se conoce como miel de grado médico a aquella que se ha estandarizado mediante irradiación de rayos gamma, filtración y eliminación de contaminantes bajo situaciones controladas en el laboratorio.

Por otra parte, en los últimos años también se ha postulado la eficacia de la combinación de un limpiador a base de EDTA con fluoroquinolonas en el tratamiento de las otitis caninas por Pseudomonas spp. (Nuttall, 2016; Wildermuth et al., 2007), ya sea usando primero el limpiador y aplicando después el antimicrobiano, o usando mezclas de ambos. Tris-EDTA afecta las membranas celulares de la bacteria con efecto quelante sobre minerales como el calcio y el magnesio, volviéndola permeable a los antimicrobianos. Existen trabajos que han demostrado que un tratamiento previo con esta solución, 20 a 30 minutos antes de la aplicación tópica de fluoroquinolona y gentamicina, resultó sumamente eficaz, aún frente a aislamientos identificados como resistentes a dichos antimicrobianos in vitro (Buckley et al., 2013). Recientemente se han comunicado resultados de trabajos realizados in vitro que reportan que el Tris-EDTA en combinación con aceites esenciales (aceite de manuka) podría ser una muy buena opción para el tratamiento de OEs crónicas en caninos producidas por gérmenes gramnegativos (Song et al., 2020).

Otro estudio realizado por von SilvaTarouca et al. (2019), describe la actividad in vitro de $1 \%$ sulfadiazina de plata frente a $P$. aeruginosa 
resistente a múltiples antimicrobianos, compuesto que suele estar contenido en formulaciones cuyo efecto bactericida se basa en su actividad osmótica que conduce al daño bacteriano de la pared celular. May et al. (2016) publicaron un estudio acerca de la eficacia in vitro de $\mathrm{N}$-acetilcisteína (NAC) sola frente a diferentes microorganismos patógenos aislados de oídos de pacientes caninos con OE, demostrando que por sí sola logró inhibir el crecimiento de dichos microorganismos in vitro. La NAC aplicada de forma tópica podría tener un efecto sinérgico con los antimicrobianos cuando se trata de infecciones causadas por $P$. aeruginosa y, más aún, frente a la presencia de biopelículas en el CAE. La NAC es un agente mucolítico que reduce, en las biopelículas, la producción de la matriz de polisacáridos extracelulares. De esta manera, la alteración de la mencionada estructura favorecería el ingreso de los antimicrobianos aplicados localmente. Sin embargo, a pesar de la existencia de algunos trabajos que avalen su eficacia, este efecto aún no ha sido estudiado extensamente (Zhao \& Liu, 2010).

\section{Terapia sistémica}

En ocasiones, se recomienda el uso de terapias sistémicas cuando se trata de otitis muy proliferativas, severas o que alcanzan el oído medio (Gotthelf, 2004; Sanchez et al., 2011). Los antimicrobianos utilizados suelen escogerse sobre la base de resultados de antibiogramas. Entre los más utilizados empíricamente están las cefalosporinas de primera generación y las fluoroquinolonas. En el caso de infección por $P$. aeruginosa suele recomendarse ciprofloxacina o marbofloxacina a dosis máxima (Penna et al., 2011; Rubin et al., 2008).

Los procedimientos quirúrgicos solo se aplican en los tumores y en los procesos muy proliferativos con estenosis del CAE (Nuttall, 2016), en este último caso, para favorecer el drenaje, la ventilación y la llegada de fármacos tópicos. Incluso en otitis proliferativas caninas se ha ensayado el uso de ciclosporina oral (Hall et al., 2003) y de corticoides intralesionales. En otros procesos crónicos o proliferativos de humanos (Caffier et al., 2007) y gatos (Mauldin et al., 2007) se ha usado el inmunosupresor tacrolimus en forma tópica, por lo que podría resultar una alternativa útil.

\section{El futuro en la terapéutica de las otitis externas por Pseudomonas aeruginosa}

Tradicionalmente, un régimen de dosificación era determinado solamente por parámetros farmacocinéticos (PK, del inglés "Pharmacokinetics"). Sin embargo, hoy se sabe que la farmacodinamia (PD, del inglés "Pharmacodynamics") desempeña también un rol de suma importancia. Es decir, la eficacia de los antimicrobianos in vivo depende de su perfil PK, como también de las propiedades PD de estos. Las concentraciones tisulares y en los fluidos orgánicos determinan los efectos farmacológicos y toxicológicos, mientras que la concentración en el sitio de infección determina el efecto antimicrobiano. De esta manera, la aplicación de modelos PK/PD, sumada a una apropiada elección de una enfermedad natural, puede proveer información relevante en cuanto a los diseños e implementación de nuevos planes terapéuticos.

Las diferencias en las especies, tanto de hospedadores como de bacterias, el estado inmunitario y la localización de la bacteria (en algunos casos, intracelular) afectarán la relación PK/PD (Mestorino, 2006). Más aún, esta relación calculada con concentraciones plasmáticas no suministra predicciones precisas de eficacia en situaciones como en la otitis externa. En este caso, las concentraciones del fármaco en el compartimento auricular son muy diferentes a las del plasma y, por otra parte, la actividad de los antimicrobianos puede ser, además, afectada por la presencia de los exudados presentes en el CAE.

Es frecuente que la selección de un agente antimicrobiano y su dosis sean efectuadas tomando en cuenta como parámetro PK los niveles de concentración plasmática total del mismo y un parámetro PD estático in vitro como su concentración inhibitoria mínima (CIM) sobre un determinado tipo de germen (Li et al., 1999). Este parámetro PD estático nos proveerá solo una limitada información acerca de la actividad de un agente antibacteriano, ya que:

- La CIM no aporta información acerca de la velocidad de la actividad antibacteriana (Craig, 1998). La velocidad de muerte bacteriana difiere según el tipo de mecanismo de acción de los antibióticos, existiendo diferencias notables entre la provocada por agentes bactericidas y bacteriostáticos (Xiong et al., 1996).

- La CIM no provee información acerca de la persistencia de la actividad antibacteriana luego del cese de la exposición del microorganismo al antibiótico (efecto postantibiótico) (Craig, 1998).

- La CIM, al referirse a una concentración constante de antimicrobiano, solo aporta información PD de tipo cualitativa, ya que hace referencia a una respuesta de tipo del todo (concentración mayor a CIM) o nada (concentración menor a CIM) (Craig, 1998).

De esta manera, la CIM no refleja totalmente el contexto in vivo, en el que las bacterias no están expuestas a una concentración constante de antibacteriano, sino que esta cambia en función del tiempo transcurrido desde su administración. Esto ocurre como consecuencia de los procesos de absorción, distribución, eliminación y excreción (Liu et al., 2005) y, en este caso en particular, como consecuencia de la inactivación in situ al 
entrar en contacto con secreciones del proceso inflamatorio.

Una de las estrategias empleadas para subsanar este inconveniente, es el estudio de las curvas de muerte bacteriana. En estas, la evolución de una población bacteriana en función del tiempo y en ausencia de antibacteriano es comparada con las curvas obtenidas en presencia de un antibiótico (Craig, 2002).

También se ha reportado que la cinética de muerte bacteriana en condiciones in vitro es modificada (aumentada o disminuida) por variaciones del $\mathrm{pH}$ y presencia de secreciones y descamaciones celulares. Se deben considerar estas variables para simular las condiciones in vivo, ya que se establecen gradientes de $\mathrm{pH}$ o bien el medio en el que se encuentran las bacterias puede ser modificado a causa de diversas alteraciones tisulares (tejidos inflamados o presencia de material necrótico) provocadas por el mismo agente infeccioso (Mestorino, 2006).

En este sentido, la PD ha evolucionado desde una concepción netamente empírica hasta una concepción cuantitativa, permitiendo describir y simular el efecto de un antibiótico sobre una población bacteriana en función del tiempo, mediante la modelización matemática de los datos experimentales (Toutain et al., 2002; Toutain \& Bousquet, 2004; Toutain \& Lees, 2004).

Por lo tanto, la construcción de curvas de muerte bacteriana para explicar la interacción fármaco-bacteria in vivo, sería un procedimiento más racional que el clásico parámetro estático de la CIM.

\section{Conclusiones}

El manejo adecuado de las otitis crónicas o recurrentes con aislamientos de Pseudomonas aeruginosa constituye un desafío constante para el veterinario clínico. En las otitis externas crónicas, la respuesta inflamatoria lesiona el estrato córneo del revestimiento epitelial del CAE y, eventualmente, se extiende hacia el pabellón auricular. La hiperplasia, tanto de las glándulas sebáceas y ceruminosas, como de la dermis y la epidermis, sumado a la presencia de exudados inflamatorios, detritus celulares y hasta cuerpos extraños, contribuyen a la reducción del diámetro de la luz del CAE. Por lo tanto, los antimicrobianos sistémicos no alcanzan concentraciones adecuadas en el sitio de infección, y es por esto que la terapia tópica representa la primera elección para el tratamiento de las otitis externas crónicas. El fracaso terapéutico viene de la mano del aumento en la cantidad de fenotipos resistentes a los antimicrobianos, lo cual constituye una grave amenaza, no solo para el paciente, sino también para el hombre y el medioambiente. El éxito de la terapéutica en el tratamiento de estas afecciones debe evolucionar hacia la aplicación de pautas $\mathrm{PK} / \mathrm{PD}$ en las que se contemple la tríada antimicrobiano-bacteria-ani- mal de una forma dinámica en función del tiempo, con objeto de maximizar la eficacia y minimizar la selección de determinantes genéticos de resistencia en la población bacteriana. El uso irracional de los antimicrobianos conduce a la búsqueda constante de nuevas alternativas terapéuticas que permitan recuperar la eficacia de estos.

Junto a los avances en el conocimiento, aparecen en escena nuevos compuestos adyuvantes del tratamiento como Tris-EDTA o NAC, incluso la puerta a la fitoterapia como terapias alternativas. Sin lugar a duda, $P$. aeruginosa en la otitis externa canina constituye uno de los principales desafíos para el manejo de los casos crónicos en los próximos años.

\section{Agradecimientos}

Agradecemos la gentileza del MV Huberto von Guradze, que nos permitió publicar fotos de su autoría.

\section{Conflicto de intereses}

Todos los autores declaran que no existe conflicto de intereses, incluyendo entre estos últimos las relaciones financieras, personales o de otro tipo, con otras personas u organizaciones que pudieran influir de manera inapropiada en el trabajo.

\section{Bibliografía}

Barnard N, Foster A. 2017. Pseudomonas otitis in dogs: a general practitioner's guide to treatment. In Practice 39:386-98. doi: 10.1136/inp.j892

Bergey D, Holt J. 1994. Bergey's manual of determinative bacteriology. $9^{\circ}$ ed. Baltimore, USA.

Berthelot P, Grattard F, Mallaval F, Ros A, Lucht F, Pozzetto B. 2005. Épidémiologie dês infections nosocomiales à Pseudomonas aeruginosa, Burkholderia cepacia et Stenotrophomonas maltophilia. Pathologie Biologie. 53 (6):341-8. doi: 10.1016/j.patbio.2004.09.006

Broglia G, Borrelli S. Enfermedades del oído. En: Brusa M. 2014. Compendio de enfermedades de los caninos y felinos domésticos. Buenos Aires, Editorial Edulp, pp. 396-413.

Buckley L, Mc Ewen N, Nuttall T. 2013. Tris-EDTA significantly enhances antibiotic efficacy against multidrug-resistant $P$. aeruginosa in vitro. Veterinary Dermatology. 24(5):519-e122.

doi: 10.1111/vde.12071 
Bugden DL. 2013. Identification and antibiotic susceptibility of bacterial isolates from dogs with otitis externa in Australia. Australian Veterinary Journal. 91(1-2):43-6. doi: 10.1111/avj.12007

Buldain D, Buchamer A, Marchetti L, Aliverti F, Borja C, Mestorino N. 2017. Efecto antimicrobiano de la combinación cloxacilina con aceite esencial de Melaleuca armillaris frente a Staphylococcus aureus. Analecta Veterinaria. 37(2):33-9.

doi: 10.24215/15142590e014

Buldain D, Buchamer AV, Marchetti ML, Aliverti F, Bandoni A, Mestorino N. 2018. Combination of cloxacillin and essential oil of Melaleuca armillaris as an alternative against Staphylococcus aureus. Veterinary Pharmacology and Toxicology, Frontiers in Veterinary Science. 5:177. doi: 10.3389/fvets.2018.00177

Cabot G, Zamorano L, Moyà B, Juan C, Navas A, Blázquez J, Oliver A. 2016. Evolution of Pseudomonas aeruginosa antimicrobial resistance and fitness under low and high mutation rates. Antimicrobial Agents and Chemotherapy 60:176778. doi: 10.1128/AAC.02676-15

Caffier P, Harth W, Mayelzadeh B, Haupt H, Sedlmaier B. 2007. Tacrolimus: a new option in therapy-resistant chronic external otitis. Laryngoscope. 117(6):1046-52. doi: 10.1097/MLG.obo13e31804b1aad

Cole L. 2009. Anatomy and physiology of the canine ear. Veterinary Dermatology. 20, 412-21. doi: 10.1111/j.1365-3164.2009.00849.x

Craig WA. 1998. Pharmacokinetic-pharmacodynamic parameters: rationale for antibiotic use in mice and men. Clinical Infectious Diseases. 26:112. doi: $10.1086 / 516284$

Craig WA. 2002. The role of pharmacodynamics in infective treatment of community-acquired pathogens. Advanced Studies in Medicine (Proceeding). 2:126-34.

Escribano C, Ordeix L, Pol G, Puigdemont A, Brazis P. 2009. Sensibilidad de Pseudomonas spp. frente a las quinolonas en infecciones óticas y cutáneas en el perro y en el gato. Clínica Veterinaria de Pequeños Animales. 29 (4):203-7.

Gómez Álvarez C, Leal Castro A, Pérez de González M, Navarrete Jiménez M. 2005. Mecanismos de resistencia en Pseudomonas aeruginosa: entendiendo a un peligroso enemigo. Revista de la Facultad de Medicina Universidad Nacional de Colombia. 53 (1):27-34.

Gotthelf L. 2004. Diagnosis and treatment of otitis media in dogs and cats. The Veterinary Clinic of
North America.Small Animal Practice. 34(2):46987. doi: 10.1016/j.cvsm.2003.10.007

Griffin C. 2011. Otitis, lo básico. Proceedings of the Southern European Veterinary Conference \& Congreso Nacional de AVEPA, Barcelona, España.

Hall JA, Waisglass S, Mathews K, Tait J. 2003. Oral cyclosporin in the treatment of end-stage ear disease: a pilot study. Veterinary Dermatology. 14:212.

Hariharan H, Coles M, Poole D, Lund L, Page R. 2006. Update on antimicrobial susceptibilities of bacterial isolates from canine and feline otitis externa. Canadian Veterinary Journal. 47(3):2535 .

Jacobson LS. 2002. Diagnosis and medical treatment of otitis externa in the dog and cat. Journal South African Veterinary Association. 73(4):162-70. doi: 10.4102/jsava.v73i4.581

Kobayashi M, Yoshida T, Takeuchi D, Jones V, Shigematsu K, Herndon D, Suzuki F. 2008. Gr-1+ CD11b+ cells as an accelerator of sepsis stemming from Pseudomonas aeruginosa wound infection in thermally injured mice. Journal Leukocite Biology. 83(6):1354-62. doi: 10.1189/jlb.0807541

Li R, Zhu M, Schentag J. 1999. Achieving an optimal outcome in the treatment of infections: The role of clinical pharmacokinetics and pharmacodynamics of antimicrobials. Clinical Pharmacokinetics. 37:1-16.

doi: 10.2165/00003088-199937010-00001

Lin D, Foley S, Qi Y, Han J, Ji C, Li R, Wu C, Shen J, Wang Y. 2012. Characterization of antimicrobial resistance of Pseudomonas aeruginosa isolated from canine infections. Journal of Applied Microbiology. 113(1):16-23.

doi: 10.1111/j.1365-2672.2012.05304.x

Liu P, Rand K, Obermann B, Derendorf H. 2005. Pharmacokinetic-pharmacodynamic modelling of antibacterial activity of cefpodoxine and cefixime in in vitro kinetic models. International Journal of Antimicrobial Agents. 25(2):120-9.

doi: 10.1016/j. ijantimicag.2004.09.012

Livemore D. 2002. Multiple mechanisms of antimicrobial resistance in Pseudomonas aeruginosa: our worst nightmare? Clinical Infectious Diseases. 34(5):634-40. doi: 10.1086/338782

Mandell GL, Bennett JE, Dolin R. 2012. Mandell, Douglas y Bennett. Enfermedades infecciosas. Principios y práctica. $7^{\circ}$ Ed. Barcelona, Elsevier España.

Maruhashi E, São Braz B, Nunes T, Pomba C, Belas A, Duarte-Correia JE, Lourenço AM. 2016. 
Efficacy of medical grade honey in the management of canine otitis externa - a pilot study. Veterinary Dermatology. 27(2):93-e27.

doi: 10.1111/vde.12291

Mauldin E, Ness T, Goldschmidt M. 2007. Proliferative and necrotizing otitis externa in four cats. Veterinary Dermatology. 18(5):370-7.

doi: 10.1111/j.1365-3164.2007.00614.X

May ER, Conklin KA, Bernis DA. Antibacterial effect of $\mathrm{N}$-acetylcysteine on common canine otitis externa isolates. 2016. Veterinary Dermatology 27(3):188-e47. doi: 10.1111/vde.12313

Mestorino N. 2006. Antibioticoterapia racional de enfermedades respiratorias en pequeños animales. Proceedings $6^{\circ}$ Congreso Nacional de AVEACA, Buenos Aires, Argentina. pp 76-87.

Neves R, Makino H, Cruz T, Silveira M, Sousa V, Dutra V, Lima $\mathrm{M}$, Belli C. In vitro and in vivo efficacy of tea tree essential oil for bacterial and yeast ear infections in dogs. 2018. Pesquisa Veterinaria Brasileira. 38(8):1597-607.

doi: 10.1590/1678-5150-PVB-5055

Ngo J, Taminiau B, Aboulaye Fall P, Daube G, Fontaine J. 2018. Ear canal microbiota - a comparison between healthy dogs and atopic dogs without clinical signs of otitis externa. Veterinary Dermatology. 29 (5):425-e140.

doi: $10.1111 /$ vde.12674

Nuttall T. 2016. Successful management of otitis externa. In Practice. 38(2):17-21.

Oliveira L, Leite C, Brilhante R, Carvalho C. 2008. Comparative study of the microbial profile from bilateral canine otitis externa. Canadian Veterinary Journal. 49(8):785-8.

Paterson S, Matyskiewicz W. 2018. A study to evaluate the primary causes associated with Pseudomonas otitis in 60 dogs. The Journal of Small Animal Practice. 59:238-42.

doi: $10.1111 /$ jsap.12813

Paterson S. 2016a. Discovering the causes of otitis externa. In Practice. 38:7-11. doi: 10.1136/inp.i470

Paterson S. 2016b. Topical ear treatment, options, indications, and limitations of current therapy. Journal of Small Animal Practice. 57(12):668-78. doi: $10.1111 /$ jsap.12583

Penna B, Thomé S, Martins R, Martins G, Lilenbaum W. 2011. In vitro antimicrobial resistance of Pseudomonas aeruginosa isolated from canine otitis externa in Rio de Janeiro, Brazil. Brazilian Journal of Microbiology. 42(4):1434-6. doi: $10.1590 / \mathrm{S} 1517-838220110004000027$
Petersen A, Walker R, Bowman M, Schott H, Rosser E Jr. 2002. Frequency of isolation and antimicrobial susceptibility patterns of Staphylococcus intermedius and Pseudomonas aeruginosa isolates from canine skin and ear samples over a 6year period (1992-1997). Journal of American Animal Hospital Association. 38(5): 407-13. doi: $10.5326 / 0380407$

Petrov V, Mihaylov G, Tsachev I, ZhelevG, Marutsov P, Koev K. 2013. Otitis externa in dogs: Microbiology and antimicrobial susceptibility. Revista de Medicina Veterinaria. 164(1):18-22.

Pulido A, Castañeda RS, Linares ML, Mercado MG. 2010. Diagnóstico clínico-microbiológico de otitis externa en caninos de Bogotá - Colombia. Revista MVZ Córdoba. 15(3):2215-22.

doi: 10.21897/rmvz.308

Rasamiravaka T, Labtani Q, Duez P, Jaziri M. 2015. The formation of biofilms by Pseudomonas aeruginosa: a review of the natural and synthetic compounds interfering with control mechanisms. BioMed Research International. 2015: 1-17.

doi: 10.1155/2015/759348

Rosychuk R, Luttgen P. Diseases of the ear. En: Ettinger S, Feldman E (eds). 200o. Textbook of veterinary internal medicine. $5^{\text {th }}$ ed. Philadelphia, W.B. Saunders. p. 986-1002.

Rubin J, Walker R, Blickenstaff K, Bodeis-Jones S, Zhao S. 2008. Antimicrobial resistance and genetic characterization of fluoroquinolone resistance of Pseudomona aeruginosa isolated from canine infections. Veterinary Microbiology. 131(1-2):164-72.

doi: 10.1016/j.vetmic.2008.02.018

Sánchez C, Calle E, Falcón P, Pinto J. 2011. Aislamiento bacteriano en casos de otitis canina y su susceptibilidad antibiótica. Revista de Investigación Veterinaria del Perú. 22 (2):161-6.

Saridomichelakis M, Farmaki R, Leontides L, Koutinas A. 2007. Aetiology of canine otitis externa: a retrospectibe study to 100 cases. Veterinary Dermatology. 18(5): 341-7.

doi: 10.1111/j.1365-3164.2007.00619.x

Scott D, Miller W, Griffin C. Diseases of eyelids, claws, anal sacs, and ears. En: Scott D, Miller W, Griffin C (eds). 2001. Muller \& Kirk's small animal dermatology. 6th ed. Philadelphia, W B Saunders.

Sim JFX, Khazandi M, Chan WY, Trott DJ, Deo P. 2019. Antimicrobial activity of thyme oil, oregano oil, thymol and carvacrol against sensitive and resistant microbial isolates from dogs with otitis externa. Veterinary Dermatology. 30(6):524-e159. doi: 10.1111/vde.12794 
Song SY, Hyun JE, Kang JH, Hwang CY. 2020. In vitro antibacterial activity of the manuka essential oil from Leptospermum scoparium combined with Tris-EDTA against Gram-negative bacterial isolates from dogs with otitis externa. Veterinary Dermatology. 31(2):81-8. doi: 10.1111/vde.12807

Terziev G, Borissov I. 2017. Prevalence of ear diseases in dogs - A retrospective 5-year clinical study. Bulgarian Journal of Veterinary Medicine. 21(1):76-85. doi: 10.15547/bjvm.1075

Toutain PL, Bousquet-Mélou A. 2004. Plasma terminal half-life. Journal Veterinary Pharmacology Therapeutics. 27(6):427-39.

doi: 10.1111/j.1365-2885.2004.00600.x

Toutain PL, Lees P. 2004. Integration and modelling of pharmacokinetic and pharmacodynamic data to optimize dosage regimens in veterinary medicine. Journal Veterinary Pharmacology Therapeutics. 27(6):467-77.

doi: 10.1111/j.1365-2885.2004.00613.x

Toutain PL, del Castillo J, Bousquet-Mélou A. 2002. The pharmacokinetic-pharmacodynamic approach to a rational dosage regimen for antibiotics. Research in Veterinary Science. 73(2): 105-14. doi: 10.1016/Soo34-5288(02)00039-5

von Silva-Tarouca M, Wolf G, Mueller R. 2019. Determination of minimum inhibitory concentrations for silver sulfadiazine and other topical antimicrobial agents against strains of Pseudomonas aeruginosa isolated from canine otitis externa. Veterinary Dermatology. 30(2):145e42. doi: 10.1111/vde.12718

Wildermuth B, Griffin C, Rosenkrantz W, Boord M. 2007. Susceptibility of Pseudomonas isolates from the ears and skin of dogs to enrofloxacin, marbofloxacin, and ciprofloxacin. Journal American Animal Hospital Association. 43(6):33741. doi: 10.5326/0430337

Xiong Y, Caillon J, Drugeon H, Potel G, Baron D. 1996. Influence of $\mathrm{pH}$ on adaptative resistance of Pseudomonas aeruginosa to aminoglycosides and their postantibiotic effects. Antimicrobiology Agents Chemotherapy. 40(1):35-9.

Zhao T, Liu Y. 2010. N-acetylcysteine inhibit biofilms produced by Pseudomonas aeruginosa. BMC Microbiology. 10:140.

doi: 10.1186/1471-2180-10-140

Zur G, Lifshitz, B, Bdolah-Abram T. 2011. The association between the signalment, common causes of canine otitis externa and pathogens. Journal of Small Animal Practice. 52(5):254-8. doi: 10.1111/j.1748-5827.2011.01058.x 